\title{
Transcranial Direct Current Stimulation Technique: A Need of Bangladesh for Stroke Management
}

\author{
Ghulam Murtaza \\ Department of Neurology, College of Medicine, King Saud University, Saudi Arabia
}

Copyright $(2017$ by authors, all rights reserved. Authors agree that this article remains permanently open access under the terms of the Creative Commons Attribution License 4.0 International License

\begin{abstract}
Stroke has been considered as one of the leading cause of death worldwide. It results in reduced excitability, deregulated plastic modifications, and formation of aberrant connections and, these factors hinder recovery from stroke. Transcranial direct current stimulation (tDCS) is a promising technique for the treatment of a wide range of neurological disorders including stroke. Its application could improve the condition of patients having neurological disorders by making functional connections and maintaining existing pathways. In Bangladesh, stroke remains the third leading cause of death with $0.3 \%$ prevalence. The number of disability-adjusted life years lost for stroke is 485 per 10000 people, which depicts great economic burden of this disease in the future. Thus, introduction of new technologies such as tDCS in the treatment of stroke will not only improve conditions of stroke patients but also reduce economic burden of this disease in Bangladesh.
\end{abstract}

Keywords Transcranial Direct Current Stimulation, Stroke, Bangladesh

\section{Introduction}

Stroke, the second leading cause of death worldwide, is considered to affect at least one sixth of all people at least once in their life [1]. Moreover, this is the third most common cause of disability in adults. About one third of patients who survive 6 months after stroke attack become dependent on others [2]. Although mortality rate due to stroke has decreased, the incidence is increasing and, is estimated to reach 23 million cases by 2030 [3]. Patients suffering from ischemic stroke require constant monitoring in intensive care units (ICU) at hospitals.

Due to stroke, cells deprive of their nutrient supply, thus resulting in immediate cells death and brain damage and, this impairment is not only confined to the brain but may also result in alteration in inflammatory immune response. Suppression of systemic immunity may increase the stroke patients' susceptibility to infections. For instance, pneumonia and urinary tract infections are the most common post stroke complications in patients [4].

\subsection{Risk Factors for Stroke}

Factors that seem to increase the risk of stroke attack are diabetes, high blood pressure as it increases a person's stroke risk by four to six times, smoking, lack of physical activity, obesity, old age, gender, high cholesterol levels, atrial fibrillation, thrombophilia, migraine with aura, heredity (family history), and prior stroke or heart attack [5]. The chances of occurring of stroke double after 55 years of age; however, it can happen at any age even in children. African-Americans have higher risks of stroke than Caucasians [6], which can be attributed to higher risks of high blood pressure, diabetes, and obesity in black people. Women have more stroke attacks and deaths due to this disease. The factors which pose stroke risks for females include pregnancy, use of birth control pills, history of preeclampsia/eclampsia or gestational diabetes, smoking, and post-menopausal hormone therapy [7]. Transient ischemic attacks (TIA) that produce stroke-like symptoms but no lasting damage are regarded as warning strokes [8]. The risk of stroke following TIA is $4 \%$ within the first 2 days, $6 \%$ within 7 days, $8 \%$ within 30 days and $9 \%$ within 90 days [9].

Limited data is available about stroke incidences from Bangladesh. However, few hospital studies have indicated high stroke prevalence in males and in age group above 70 years [10]. Number of patients having ischaemic stroke is higher than that of having hemorrhagic stroke. The main risk factors observed in stroke patients include hypertension which is the main risk factor followed by heart diseases, diabetes mellitus, obesity, hyperlipidemia, prior stroke attack, cigarette smoking, alcohol consumption, and oral contraception use. Moreover, some of the patients had multiple risk factors $[10,11]$. Interestingly, several nontraditional risk factors, for instance, water-pipe use, desi (country-made) ghee (a class of clarified butter), chewable 
tobacco, and infectious causes of stroke are under investigated. Moreover, there is still need to know exactly about the happening of stroke incidences and to gather findings of existing stroke risk factors in Bangladesh.

\subsection{Symptoms of Stroke}

The symptoms linked with stroke are numbness or weakness in the arm, leg or face, particularly on one side of the body, dizziness, loss of balance, lack of coordination, difficulty in walking, seeing, speaking or understanding speech, and sudden severe headache with no known cause. Even symptoms of stroke may disappear after few hours of stroke. However, it does not guarantee that stroke attack will not occur again. Thus, in case of above-mentioned symptoms, one should immediately go for medical assistance to minimize risk of brain damage and, to avoid progression of stroke to other areas of brain [12].

\subsection{Consequences of Stroke}

Patients with stroke have a wide range of impairments and a broad spectrum of symptom severity. Stroke can result in several neurological disorders and even can lead to death if remains undiagnosed and untreated promptly. Generally, stroke causes damage to local areas of the brain, however bleeding and increase in intracranial pressure in the brain can harm whole brain, which may lead to severe conditions [13]. Swallowing is another problem faced by patients after stroke, which may lead to choking if food enters the airways [14].

In case of severe attack of stroke, patients need to admit to the hospital, and how long they will stay there, it depends upon the severity of stroke and rehabilitation of the patients. Their long stay at hospital will cause shortage of space as well as of doctors for new patients. Sometimes, this care is provided at home by family members or a nursing home. In Saudi Arabia, it takes mean 45 days for rehabilitation of stroke patients [15]. In Bangladesh, mean stay of patients at hospital is 8 days [11]. Hospital stay may also be increased if patients suffer from stroke along with other diseases such as diabetes mellitus and hypertension [16]. Stroke patients may lose their job and instead of supporting themselves and other family members, they will depend upon them. This effect can significantly be seen in those societies where joint family system is present, for instance in Bangladesh where one person is supporting his wife and children. Moreover, stroke significantly impairs quality of life of suffering persons, as depression, stress, and anxiety are common in these people. Moreover, it is difficult for them to self-care, move, and perform usual activities [17]. In Bangladesh, post stroke psychological distress (depression, anxiety, and stress) was detectable among the stroke survivors. A higher proportion of females are hypertensive after stroke [18].

\subsection{Diagnosis of Stroke}

Stroke can be diagnosed in different ways, for instance, by checking of blood pressure level, as stroke can increase it significantly, electrocardiograms to check heart function, blood tests to check clotting, cholesterol, and blood sugar levels. Brain scan with computed tomography and magnetic resonance imaging (MRI) scans is another method to diagnose the stroke. Swallow test is also performed for diagnosis, as many stroke patients have difficulty in swallowing [14]. Tests used later with disease progression to determine the extent of the damage are carotid Doppler tests, chest x-rays, and echocardiograms [19, 20].

\subsection{Treatment and Rehabilitation}

Brain cells need constant supply of oxygen for their health and better functioning [21]. Interruption of supply only for a short period can lead to death of a person. Thus, it is vital to provide prompt attention and assistance to the affected person as soon as possible to save his life. For the recovery of stroke patient, a stroke team will create an individual rehabilitation program designed according to patient's needs. Rehabilitation treatments include physiotherapy, occupational therapy, speech and language therapy, and vision correction [22].

\section{Transcranial Direct Current Stimulation}

Transcranial direct current stimulation (tDCS) is a non-invasive, painless, and safe [23] brain stimulation employed in the treatment of neuropsychiatric conditions. A constant current stimulator and surface electrodes soaked in normal saline are required for tDCS. The typical target for treatment is placement of anode over the right prefrontal cortex and cathode over the left prefrontal cortex. Anodal electrodes increase excitability and cathode electrode decreases excitability. The current stimulator is the source of steady flow of 0-4 mA direct current and it constantly monitors the resistance in the system. Saline soaked electrodes applied and secured onto the scalp over desired areas [(e.g. the left or right precentral gyrus region (corresponding to $\mathrm{C} 3$ or $\mathrm{C} 4$ of the international 10-20 EEG system)] make terminal relaying currents across the scalp and via the underlying brain tissue. When switched on, the current stimulator generates a transient tingling sensation under the electrode which disappears in $30 \mathrm{sec}$ to $1 \mathrm{~min}$ thereby making it optimal for blinding subjects (in sham-controlled studies) by turning it off after the initial sensory experience. As demonstrated in a previous work, current densities $25 \mathrm{~mA} / \mathrm{cm}^{2}$ do not damage brain tissue, thus application of 1-2 $\mathrm{mA} / \mathrm{cm}^{2}$ current is absolutely safe [24]. Although, very low density of current is administered to underlying cortex in tDCS, however previous works have demonstrated it enough for neuronal excitability shifts [25]. Even in a previous study [26], change in measures of cerebral blood flow in brain regions exposed to tDCS has been demonstrated, thus indicating changes in regional tissue 
excitability through this procedure. The application of tDCS is advantageous over other stimulation methods because of its important properties, which include its ease of use, large size of electrodes, its portability making stimulation possible when and where needed, a sham mode, which allows conductance of controlled experiments and randomized controlled clinical trials. However, its poor temporal resolution and anatomical localization are its limitations. Moreover, inter-individual variation in conductivity due to differences in hair, scalp, and bone composition can hinder the current transmission to the brain.

tDCS is being administered in the treatment of stroke in different parts of the world. However, few investigations/treatments do not cite it as effective. For instance, studies carried out with post-stroke aphasia and stroke patients did not demonstrate improvement of conditions of patients using tDCS [27-29]. On the other hand, many studies have signified employment of tDCS in the treatment of patients with different neurological disorders (Table 1). The difference in response to tDCS can be ascribed to severity of neurological disorders and differences in areas of the brain that were exposed to stimulation by tDCS [30]. Studies using tDCS promise its application for manipulation of emotions regulation and decision-making in humans [31]. However, further investigations particularly involving humans are required to understand and authenticate tDCS's actions on the brain, its mechanisms, and the associated behavioral and cognitive impacts.

Table 1. Using transcranial direct current stimulation for stroke rehabilitation

\begin{tabular}{|c|c|c|}
\hline Author & Disease investigated & Improvement \\
\hline Ahn YH, 2016 [45] & post-stroke dysphagia & yes \\
\hline Ilić NV, 2016 [46] & stoke & yes \\
\hline Darkow R, 2016 [47] & post-stroke aphasia & yes \\
\hline Kirton A, 2016 [48] & perinatal stroke & yes \\
\hline Valiengo LC, 2016 [49] & post-stroke depression & yes \\
\hline Chang MC, 2015 [50] & subacute stroke & yes \\
\hline Elsner B, 2015 [28] & post-stroke aphasia & no \\
\hline Au-Yeung SS, 2014 [51] & paretic hand after & yes \\
\hline O'Shea J, 2014 [52] & chronic stroke & yes \\
\hline Lefebvre S, 2014 [53] & chronic stroke & yes \\
\hline Fusco A, 2013 [54] & subacute stroke & yes \\
\hline Elsner B, 2013 [27] & stroke & no \\
\hline Rossi C, 2013 [29] & acute stroke & no \\
\hline Danzl MM, 2013 [55] & chronic stroke & yes \\
\hline Ochi M, 2013 [56] & chronic stroke & yes \\
\hline
\end{tabular}

\section{Human and Economic Burden of Stroke}

Stroke is a costly disorder from individual to social perspectives. It is one of the leading causes of death and disability in the world. In 2005, about 16 million first-ever strokes were registered in the world with 5.7 million deaths, which are expected to rise to 23 million first-ever strokes and 7.8 million deaths by 2030 [3]. In the United States, findings indicate 5,800,000 prevalent stroke cases. More than 780,000 first-ever or recurrent strokes are expected to occur each year [32]. In 15-country Europe, figures demonstrate 2,700,000 prevalent cases and 536,000 incident cases each year. In 48-European countries, number of deaths due to stroke is estimated at $1,239,000$ per year [33]. Stroke is by no way is considered a problem of western or developed countries. About $85 \%$ of all stroke deaths are reported in low- and middle-income countries [34]. In South Asian countries including Bangladesh, 40\% deaths are estimated due to stroke [35]. In Bangladesh, stroke is the third leading cause of death with $0.3 \%$ prevalence [18].

In terms of economic burden, stroke has a huge effect with about $5 \%$ of the medical costs of industrialised countries are given to disease. The long-term disorders left behind after stroke attack are hugely detrimental with respect to both hospital and other care sector costs. Previously, stroke prevalence was relatively high in the developed countries. Recently, the stroke incidence in low- and middle-income countries has exceeded that than that of high-income countries by about 20\% [36]. Rapid urbanization, low physical activities, and increasing habits of smoking can further increase the risk of stroke in these countries [37].

The concerns regarding economic burden of stroke include initial hospitalization, medications, continuing medical care, productivity loss, and work limitations. Over a lifetime, the cost of an ischemic stroke in the United States is over $\$ 140,000$ including hospital admissions, rehabilitation, and long-term care and treatment for lasting disorders [38] and, direct annual stroke-related medical costs are expected to increase to $\$ 184.13$ billion by 2030 [39].

In Canada, about 62,000 strokes cases are reported per year. More than 400,000 stroke survivors are living with long-term stroke disability. The costs to the Canadian economy are $\$ 2.7$ billion a year with an average of $\$ 27,500$ being spent per stroke on acute care. Stroke sufferers spend in total 3,000,000 days in hospital per year, which is a severe drain on the economy [5].

In the United Kingdom, about 152,145 stroke cases are reported every year. Up to 13 per 100,000 children suffer with stroke. It is thought there are around 400 childhood strokes a year in the United Kingdom [40]. It is estimated that health and social care costs are approximately $£ 4.38$ billion and informal care expenses are $£ 2.42$ billion. Productivity losses (i.e., income lost) due to care, disability and death are approximately $£ 1.33$ billion, and benefit payments are approximately £841millio per year, respectively. Total cost from a societal perspective is estimated to be around $£ 9$ billion a year [41].

Bangladesh is one of the poorest, least developed, low-income, and densely populated countries in the world. In 
this country, prevalence of stroke is high. Limited acute stroke care i.e., thrombolysis and stroke units are available to stroke patients. Public awareness about stroke, physician training, and research facilities are inadequate. Moreover, country lacks prevention strategies at the Government level [42]. Total healthcare expenditure stands at only $3.7 \%$ of total GDP of the economy, which is less compared to developed countries. There are about 2213 hospitals with only 60 registered and trained neurologists. Neurology training programs are only offered in few hospitals [43]. This situation is dismal for Bangladeshi stroke patients as the mortality rate due to stroke is increasing. Despite major advances in the scientific understanding, technology, and management of stroke globally, Bangladesh is still suffering stroke and its aftereffects. The high number of disability-adjusted life-years lost due to stroke (485 per 10,000 people) show that stroke has severe impacts on the economy of Bangladesh. Two non-governmental organizations, BRAC and the center for the rehabilitation of the paralyzed, have taken initiative in primary stroke prevention strategies. However, the Bangladeshi Government needs to emphasize healthcare development to cope with the increasing population density and to reduce stroke risk factors and its occurrence [18].

\section{Conclusions}

Acute and post-discharge treatments are indispensable to avoid the natural trend of rise of human, economic, and social burden of stroke. The rising burden of stroke particularly in low- and middle-income countries leads to propose a worldwide goal for stroke: reduction of about $2 \%$ stroke cost each year is achievable following better case management and treatment. Experience of high-income countries demonstrates that about $4 \%$ annual average declines in stroke mortality is achievable [3]. Introduction of latest technologies such as tDCS in stroke management can play a significant role against stroke and its impacts, as a prognostic technique as well as a rehabilitative method [44]. In summary, the high mortality and permanent disability due to stroke coupled with costly treatments makes it crucial that better stroke management and treatment is freely accessible and implemented. tDCS can play a vital role in these improvements. Introduction of tDCS in the treatment/management of stroke in Bangladesh will not only be helpful for stroke patients but also reduce burden of government for spending a lot of money on stroke management.

\section{REFERENCES}

[1] Seshadri S, Beiser A, Kelly-Hayes M, Kase CS, Au R, Kannel WB, Wolf PA. The lifetime risk of stroke: estimates from the
Framingham Study. Stroke 2006, 37(2):345-350.

[2] Warlow CP. Epidemiology of stroke. Lancet 1998, 352 Suppl 3:SIII1-4.

[3] Strong K, Mathers C, Bonita R. Preventing stroke: saving lives around the world. Lancet Neurol 2007, 6(2):182-187.

[4] Santos Samary C, Pelosi P, Leme Silva P, Rieken Macedo Rocco P. Immunomodulation after ischemic stroke. Potential mechanisms and implications for therapy. Crit Care 2016, 20(1):391.

[5] Sacco RL, Kasner SE, Broderick JP, Caplan LR, Connors JJ, Culebras A, Elkind MS, George MG, Hamdan AD, Higashida RT, Hoh BL, Janis LS, Kase CS, Kleindorfer DO, Lee JM, Moseley ME, Peterson ED, Turan TN, Valderrama AL, Vinters HV; American Heart Association Stroke Council, Council on Cardiovascular Surgery and Anesthesia; Council on Cardiovascular Radiology and Intervention; Council on Cardiovascular and Stroke Nursing; Council on Epidemiology and Prevention; Council on Peripheral Vascular Disease; Council on Nutrition, Physical Activity and Metabolism. An updated definition of stroke for the 21st century: a statement for healthcare professionals from the American Heart Association/American Stroke Association. Stroke 2013, 44(7):2064-2089.

[6] Norris KC, Mensah GA, Boulware LE, Lu JL, Ma JZ, Streja E, Molnar MZ, Kalantar-Zadeh K, Kovesdy CP. Age, Race and Cardiovascular Outcomes in African American Veterans. Ethn Dis 2016, 26(3):305-314.

[7] Bushnell CD. Stroke in women: risk and prevention throughout the lifespan. Neurol Clin 2008, 26(4):1161-1176, xi.

[8] Valls J, Peiro-Chamarro M, Cambray S, Molina-Seguin J, Benabdelhak I, Purroy F. A Current Estimation of the Early Risk of Stroke after Transient Ischemic Attack: A Systematic Review and Meta-Analysis of Recent Intervention Studies. Cerebrovasc Dis 2016, 43(1-2):90-98.

[9] Johnston SC, Rothwell PM, Nguyen-Huynh MN, Giles MF, Elkins JS, Bernstein AL, Sidney S. Validation and refinement of scores to predict very early stroke risk after transient ischaemic attack. Lancet 2007, 369(9558):283-292.

[10] Mohammad QD, Habib M, Hoque A, Alam B, Haque B, Hossain S, Rahman KM, Khan SU. Prevalence of stroke above forty years. Mymensingh Med J 2011, 20(4):640-644.

[11] Bhowmik NB, Abbas A, Saifuddin M, Islam MR, Habib R, Rahman A, Haque MA, Hassan Z, Wasay M. Ischemic Strokes: Observations from a Hospital Based Stroke Registry in Bangladesh. Stroke Res Treat 2016, 2016:5610797.

[12] Caproni S, Colosimo C. Movement disorders and cerebrovascular diseases: from pathophysiology to treatment. Expert Rev Neurother 2016:1-11.

[13] Bonds BW, Hu P, Li Y, Yang S, Colton K, Gonchigar A, Cheriyan J, Grissom T, Fang R, Stein DM. Predictive value of hyperthermia and intracranial hypertension on neurological outcomes in patients with severe traumatic brain injury. Brain Inj 2015, 29(13-14):1642-1647.

[14] Arnold M, Liesirova K, Broeg-Morvay A, Meisterernst J, Schlager M, Mono ML, El-Koussy M, Kagi G, Jung S, Sarikaya H. Dysphagia in Acute Stroke: Incidence, Burden 
and Impact on Clinical Outcome. PLoS One 2016, 11(2):e0148424.

[15] Al-Jadid MS, Robert AA. Determinants of length of stay in an inpatient stroke rehabilitation unit in Saudi Arabia. Saudi Med J 2010, 31(2):189-192.

[16] Al-Eithan MH, Amin M, Robert AA. The effect of hemiplegia/hemiparesis, diabetes mellitus, and hypertension on hospital length of stay after stroke. Neurosciences (Riyadh) 2011, 16(3):253-256.

[17] Prlic N, Kadojic D, Kadojic M. Quality of life in post-stroke patients: self-evaluation of physical and mental health during six months. Acta Clin Croat 2012, 51(4):601-608.

[18] Islam MN, Moniruzzaman M, Khalil MI, Basri R, Alam MK, Loo KW, Gan SH. Burden of stroke in Bangladesh. Int J Stroke 2013, 8(3):211-213.

[19] Filippi M, Agosta F. Diffusion tensor imaging and functional MRI. Handb Clin Neurol 2016, 136:1065-1087.

[20] Jensen MK, Havndrup O, Christiansen M, Andersen PS, Axelsson A, Kober L, Bundgaard H. Echocardiographic evaluation of pre-diagnostic development in young relatives genetically predisposed to hypertrophic cardiomyopathy. Int J Cardiovasc Imaging 2015, 31(8):1511-1518.

[21] Lee JM, Grabb MC, Zipfel GJ, Choi DW. Brain tissue responses to ischemia. J Clin Invest 2000, 106(6):723-731.

[22] Duncan PW, Zorowitz R, Bates B, Choi JY, Glasberg JJ, Graham GD, Katz RC, Lamberty K, Reker D. Management of Adult Stroke Rehabilitation Care: a clinical practice guideline. Stroke 2005, 36(9):e100-143.

[23] Nitsche MA, Cohen LG, Wassermann EM, Priori A, Lang N, Antal A, Paulus W, Hummel F, Boggio PS, Fregni F, Pascual-Leone A. Transcranial direct current stimulation: State of the art 2008. Brain Stimul 2008, 1(3):206-223.

[24] Mccreery DB, Agnew WF, Yuen TGH, Bullara L. Charge-Density and Charge Per Phase as Cofactors in Neural Injury Induced by Electrical-Stimulation. Ieee T Bio-Med Eng 1990, 37(10): 996-1001.

[25] Wagner T, Fregni F, Fecteau S, Grodzinsky A, Zahn M, Pascual-Leone A. Transcranial direct current stimulation: a computer-based human model study. Neuroimage 2007, 35(3):1113-1124

[26] Schlaug G, Renga V, Nair D. Transcranial direct current stimulation in stroke recovery. Arch Neurol 2008, 65(12):1571-1576.

[27] Elsner B, Kugler J, Pohl M, Mehrholz J. Transcranial direct current stimulation (tDCS) for improving aphasia in patients after stroke. Cochrane Database Syst Rev 2013(6):CD009760.

[28] Elsner B, Kugler J, Pohl M, Mehrholz J. Transcranial direct current stimulation (tDCS) for improving aphasia in patients with aphasia after stroke. Cochrane Database Syst Rev 2015(5):CD009760.

[29] Rossi C, Sallustio F, Di Legge S, Stanzione P, Koch G. Transcranial direct current stimulation of the affected hemisphere does not accelerate recovery of acute stroke patients. Eur J Neurol 2013, 20(1):202-204.
[30] Clemens B, Jung S, Mingoia G, Weyer D, Domahs F, Willmes $\mathrm{K}$. Influence of anodal transcranial direct current stimulation (tDCS) over the right angular gyrus on brain activity during rest. PLoS One 2014, 9(4):e95984.

[31] Sellaro R, Nitsche MA, Colzato LS. The stimulated social brain: effects of transcranial direct current stimulation on social cognition. Ann N Y Acad Sci 2016, 1369(1):218-239.

[32] Lloyd-Jones D, Adams R, Carnethon M, De Simone G, Ferguson TB, Flegal K, Ford E, Furie K, Go A, Greenlund K, Haase N, Hailpern S, Ho M, Howard V, Kissela B, Kittner S, Lackland D, Lisabeth L, Marelli A, McDermott M, Meigs J, Mozaffarian D, Nichol G, O'Donnell C, Roger V, Rosamond W, Sacco R, Sorlie P, Stafford R, Steinberger J, Thom T, Wasserthiel-Smoller S, Wong N, Wylie-Rosett J, Hong Y; American Heart Association Statistics Committee and Stroke Statistics Subcommittee. Heart disease and stroke statistics 2008 update - A report from the American Heart Association Statistics Committee and Stroke Statistics Subcommittee. Circulation 2008, 117(4):E25-E146

[33] Launer LJ, Hofman A. Frequency and impact of neurologic diseases in the elderly of Europe: A collaborative study of population-based cohorts. Neurology 2000, 54(11 Suppl 5):S1-8.

[34] Lopez AD, Mathers CD, Ezzati M, Jamison DT, Murray CJ. Global and regional burden of disease and risk factors, 2001: systematic analysis of population health data. Lancet 2006, 367(9524):1747-1757.

[35] Kulshreshtha A, Anderson LM, Goyal A, Keenan NL. Stroke in South Asia: a systematic review of epidemiologic literature from 1980 to 2010. Neuroepidemiology 2012, 38(3):123-129.

[36] Feigin VL, Lawes CM, Bennett DA, Barker-Collo SL, Parag V. Worldwide stroke incidence and early case fatality reported in 56 population-based studies: a systematic review. Lancet Neurol 2009, 8(4):355-369.

[37] Stein AD, Thompson AM, Waters A. Childhood growth and chronic disease: evidence from countries undergoing the nutrition transition. Matern Child Nutr 2005, 1(3):177-184.

[38] Taylor TN, Davis PH, Torner JC, Holmes J, Meyer JW, Jacobson MF. Lifetime cost of stroke in the United States. Stroke 1996, 27(9):1459-1466.

[39] Ovbiagele B, Goldstein LB, Higashida RT, Howard VJ, Johnston SC, Khavjou OA, Lackland DT, Lichtman JH, Mohl S, Sacco RL, Saver JL, Trogdon JG; American Heart Association Advocacy Coordinating Committee and Stroke Council. Forecasting the future of stroke in the United States: a policy statement from the American Heart Association and American Stroke Association. Stroke 2013, 44(8):2361-2375.

[40] Mallick AA, O'Callaghan FJ. The epidemiology of childhood stroke. Eur J Paediatr Neurol 2010, 14(3):197-205.

[41] Saka O, McGuire A, Wolfe C. Cost of stroke in the United Kingdom. Age Ageing 2009, 38(1):27-32.

[42] Wasay M, Khatri IA, Kaul S. Stroke in South Asian countries. Nat Rev Neurol 2014, 10(3):135-143.

[43] Mateen FJ. International issues: neurology in Bangladesh. Neurology 2010, 74(2):e5-8.

[44] Kubis N. Non-Invasive Brain Stimulation to Enhance Post-Stroke Recovery. Front Neural Circuits 2016, 10:56. 
[45] Ahn YH, Sohn HJ, Park JS, Ahn TG, Shin YB, Park M, Ko SH, Shin YI. Effect of bihemispheric anodal transcranial direct current stimulation for dysphagia in chronic stroke patients: A randomized clinical trial. J Rehabil Med 2016.

[46] Ilic NV, Dubljanin-Raspopovic E, Nedeljkovic U, Tomanovic-Vujadinovic S, Milanovic SD, Petronic-Markovi c I, Ilic TV. Effects of anodal tDCS and occupational therapy on fine motor skill deficits in patients with chronic stroke. Restor Neurol Neurosci 2016, 34(6): 935-945.

[47] Darkow R, Martin A, Wurtz A, Floel A, Meinzer M. Transcranial direct current stimulation effects on neural processing in post-stroke aphasia. Hum Brain Mapp 2016.

[48] Kirton A, Ciechanski P, Zewdie E, Andersen J, Nettel-Aguirre A, Carlson H, Carsolio L, Herrero M, Quigley J, Mineyko A, Hodge J, Hill M. Transcranial direct current stimulation for children with perinatal stroke and hemiparesis. Neurology 2016.

[49] Valiengo LC, Goulart AC, de Oliveira JF, Bensenor IM, Lotufo PA, Brunoni AR. Transcranial direct current stimulation for the treatment of post-stroke depression: results from a randomised, sham-controlled, double-blinded trial. J Neurol Neurosurg Psychiatry 2016.

[50] Chang MC, Kim DY, Park DH. Enhancement of Cortical Excitability and Lower Limb Motor Function in Patients with Stroke by Transcranial Direct Current Stimulation. Brain Stimul 2015, 8(3):561-566.
[51] Au-Yeung SS, Wang J, Chen Y, Chua E. Transcranial direct current stimulation to primary motor area improves hand dexterity and selective attention in chronic stroke. Am J Phys Med Rehabil 2014, 93(12):1057-1064.

[52] O'Shea J, Boudrias MH, Stagg CJ, Bachtiar V, Kischka U, Blicher JU, Johansen-Berg H. Predicting behavioural response to TDCS in chronic motor stroke. Neuroimage 2014, 85 Pt 3:924-933.

[53] Lefebvre S, Thonnard JL, Laloux P, Peeters A, Jamart J, Vandermeeren Y. Single session of dual-tDCS transiently improves precision grip and dexterity of the paretic hand after stroke. Neurorehabil Neural Repair 2014, 28(2):100-110.

[54] Fusco A, De Angelis D, Morone G, Maglione L, Paolucci T, Bragoni M, Venturiero V. The ABC of tDCS: Effects of Anodal, Bilateral and Cathodal Montages of Transcranial Direct Current Stimulation in Patients with Stroke-A Pilot Study. Stroke Res Treat 2013, 2013:837595.

[55] Danzl MM, Chelette KC, Lee K, Lykins D, Sawaki L. Brain stimulation paired with novel locomotor training with robotic gait orthosis in chronic stroke: a feasibility study. NeuroRehabilitation 2013, 33(1):67-76.

[56] Ochi M, Saeki S, Oda T, Matsushima Y, Hachisuka K. Effects of anodal and cathodal transcranial direct current stimulation combined with robotic therapy on severely affected arms in chronic stroke patients. J Rehabil Med 2013, 45(2):137-140. 